\title{
The First Year of B.Sc. Chemistry at the University of Freiburg, Germany: A Report from the Experimental Lecture on General and Inorganic Chemistry
}

\author{
Ingo Krossing*
}

\begin{abstract}
The organization, content and rationale behind the 'Experimental Lecture General and Inorganic Chemistry' as well as its theoretical 'Consolidation Lecture' companion as the first contact of students in the B.Sc. program in Chemistry and Chemical Education as well as several others, i.e. Pharmacy, Geosciences, Molecular Medicine and Physics is described. To cope with the multifaceted demands on this first semester lecture series by several faculties, the experimental lecture is attended also by students from other fields. The companion lecture that addresses the advanced needs of chemists, consolidates the content of the experimental lecture by going more into detail and extends on the theories/concepts/reactions. An integrated interplay between experiment and theory is realized in our specially equipped lecture hall.
\end{abstract}

Keywords: B.Sc. Chemistry · Experimental Lecture General and Inorganic Chemistry · General chemistry · Inorganic chemistry

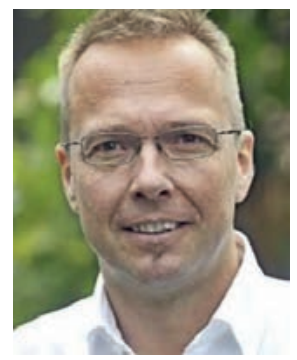

Ingo Krossing studied chemistry in Munich (LMU) and finished his doctoral thesis in 1997 (with Prof. H. Nöth). From 1997 to 1999, he worked as a Feodor Lynen postdoc with Prof. J. Passmore at UNB in Fredericton, New Brunswick, Canada. In 1999, he started his independent career as a Liebig-, and later a DFG-HeisenbergFellow at the Universität Karlsruhe (TH, now KIT) (mentor: Prof. H. Schnöckel). In 2004 he changed as an assistant professor to the Ecole Polytechnic Federale de Lausanne (EPFL), before being appointed Chair of Inorganic Chemistry at the Albert-Ludwigs-Universität Freiburg in 2006. His research interests cover ionic systems from reactive cations to ionic liquids, over electrochemical energy storage to the development of unified acidity and reducity scales.

Due to its central position for the curriculum of many degree programs in the natural, engineering and life sciences, chemistry as a field is sometimes addressed as 'The Central Science'. This reflects on the needs for other degree programs to include to a certain extent a general chemistry course. Here we describe how this is achieved as a multipurpose endeavour at the Albert-LudwigsUniversität Freiburg (ALU).

\section{Integration of the AAC-Lecture Series into Several Degree Programs at ALU}

To cope with the wishes, our possibilities and the clear demands of several degree programs that include the need for chemistry lectures at ALU, we have set up a limited set of AAClectures with, in part, multipurpose use $(\mathrm{AAC}=$ Allgemeine und Anorganische Chemie or General and Inorganic Chemistry). The structure and dependencies between the two main lectures and the students from the programs attending these courses are graphically shown in Fig. 1.

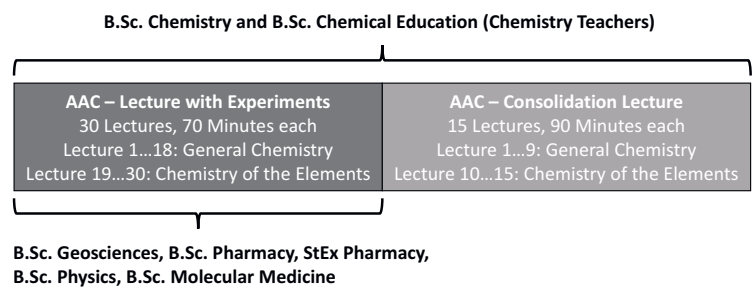

Fig. 1. Integration of the Lecture Series $A A C$ - General and Inorganic Chemistry to other degree programs.

Thus, the full 45 lectures including the $A A C$ - Experimental Lecture General and Inorganic Chemistry (from now on AAClecture) and its theoretical AAC - Consolidation Lecture companion (from now on AAC-companion) are only mandatory for students in the degree programs B.Sc. Chemistry and Chemical Education. In addition, students of the degree programs in Pharmacy (B.Sc. and State Examination = StEx) often voluntarily visit the complete lecture series. Students in the degree programs of Pharmacy, B.Sc. Geosciences and B.Sc. Physics have to visit the full 30 lectures of the AAC-lecture and students in the program B.Sc. Molecular Medicine only the first 18 lectures on General Chemistry within this series. Overall, typically around 400-450 students join the experimental lecture series and each set of students has their independent written exams. Thus, the organization of overall more than a dozen written tests and retests is the obligatory work load of the two lecturers. In addition, and to cope with the increasing demand, we had to set up a second experimental 
lecture series for students of the B.Sc./B.Eng. programs Biology, Environmental Natural Sciences and Microsystems Engineering, which is attended by about 350 students (30 lectures). The latter is not discussed here.

\section{Integration of AAC-Lecture and AAC-Companion into the Degree Program B.Sc. Chemistry}

Before describing in more detail the content of and philosophy behind the two AAC lectures, a schematic overview of the structure of the degree program B.Sc. Chemistry shall be given (Fig. 2). The degree program comprises a broad chemical education with the three compulsory pillars inorganic, organic and physical chemistry and an elective pillar that may either be biochemistry or macromolecular chemistry. In addition, calculation methods (math), physics and a $\mathrm{BOK}$ section (BOK = profession-oriented competences) on legal studies, toxicology as well as a course from the Centre for Key Competences are mandatory. The $6^{\text {th }}$ semester is almost completely devoted to independent research work, typically under the supervision of a doctoral researcher. Thus, the bachelor thesis is often intermingled with the method course for the thesis work and ends with the final public presentation of the results. The latter is done at our institute with a $15+5$ minutes presentation + discussion as part of a one-day institute symposium. The students appreciate this style as a way of acknowledging their input.

From Fig. 2 it is clear that our program stands in the tradition of the lab-work oriented chemistry program at German universities. In addition, it is worth to mention that with the conversion from the old Diplom to the current B.Sc. program, the first contact of students to true research work starts about a year earlier and, with the character of the B.Sc. thesis work as an independent research thesis, this contact is rather intense. Consequently, many B.Sc. projects are integrated in essence into follow-up publications with the students as co-authors.

\subsection{Integration of AAC-Lecture and AAC-Companion into the First Year of the B.Sc. Chemistry}

The overarching goal of the first year in the program is to transform students from being pupils with often very varying school backgrounds to independent students with the necessary competences to cope with the demands of their degree program. In addition, and since in our program the only university entrance qualification is passing the 'Abitur' = A-levels, a selection process on the subject is involved with the goal that the students that pass the first full year are qualified to pass the entire degree program. Typically, about half of the students that register for the program also complete the B.Sc. degree. To achieve this goal and to remind the students very early that a university education is different to school, a combined effort between the three major lectures in the $1^{\text {st }}$ semester is undertaken: Already after five weeks, the so-called 'Shot across the bow' exam is taken. It comprises a single written exam ( $2 \mathrm{~h}$ time) with topics from the two AAC-lectures, the OC I organic chemistry and the calculation methods of physical chemistry lectures. The weighting of the questions between the different subjects follows the number of weekly semester hours, i.e. a ratio of 5:3:3 for the achievable points from AAC:OC I:PC. This exam is part of the mandatory qualification for the lab practical/ seminar 'Introductory Course Chemical Procedures' that starts straight in the New Year after January $6^{\text {th }}$ (ALU starts the chemistry program only in fall semesters in mid-October). Since this is their first exam as students, the weighting of this examination is lower (only one third). The second written exam again as a joint effort between the three lecture courses and with equal style and weights is taken shortly before the Christmas break. It bears a weighting of two thirds for the admission to the lab practical. This selection is a black and white process of pass or fail and does not enter the grades for the degree program. Typically, half of the points or more must be reached as a weighted average of both examinations to be admitted to the lab course. Students that fail, continue attending the lecture, or in part give up. In any event, they have the chance to get admission to the lab practical by passing the graded final written exam of the AAC-lectures after the end of the semester (end of February, beginning of March). The final examinations are taken separately in each of the three lecture series; to be admitted to the lab practical, one only has to pass the AAClecture final written exam, either directly or after the retest in early April. To allow for a regular progress of the degree program of

\begin{tabular}{|c|c|c|c|c|c|c|c|c|c|}
\hline & Inorganic Chemistry & ECTS & Organic Chemistry & ECTS & Physical Chemistry & ECTS & Physics / Elective / BOK & ECTS & ECTS \\
\hline \multirow{2}{*}{ 1. Se } & $\begin{array}{c}\text { AAC - General and Inorganic } \\
\text { Chemistry (Lecture) }\end{array}$ & 7 & OC I - Organic Chemistry I (Lecture) & 5 & $\begin{array}{l}\text { Calculation Methods of Physical } \\
\text { Chemistry I (Lecture) }\end{array}$ & 6 & $\begin{array}{l}\text { Introduction to Physics with } \\
\text { Experiments (Lecture) }\end{array}$ & 8 & \multirow[b]{2}{*}{33} \\
\hline & $\begin{array}{c}\text { Introductory Course Chemical } \\
\text { Procedures (Lab Practical + Seminar) }\end{array}$ & 3 & & & & & $\begin{array}{l}\text { Physics for Natural Scientists (Lab } \\
\text { Practical) }\end{array}$ & 4 & \\
\hline \multirow{2}{*}{ 2. Se } & Analytical Chemistry (Lecture) & 4 & OC II - Organic Chemistry II (Lecture) & 6 & $\begin{array}{l}\text { Calculation Methods of Physical } \\
\text { Chemistry II (Lecture) }\end{array}$ & 7 & & & \multirow[b]{2}{*}{32} \\
\hline & $\begin{array}{l}\text { Analytical Chemistry (Lab } \\
\text { Practical+Seminar) }\end{array}$ & 6 & & & $\begin{array}{c}\text { PC I - Physical Chemistry I } \\
\text { (Lecture) }\end{array}$ & 9 & & & \\
\hline \multirow{2}{*}{ 3. Se } & $\begin{array}{l}\text { AC I - Non Metal Chemistry } \\
\text { (Lecture) }\end{array}$ & 4 & Reaction Mechanisms (Lecture) & 7 & $\begin{array}{l}\text { PC II - Physical Chemistry II } \\
\text { (Lecture) }\end{array}$ & 9 & BOK - Legal Studies & 4 & \\
\hline & & & & & $\begin{array}{c}\text { PCG - Physical Chemistry (Lab } \\
\text { Practical + Seminar) }\end{array}$ & 6 & & & 30 \\
\hline \multirow{3}{*}{ 4. Se } & $\begin{array}{l}\text { AC II - Chemistry of the Metals } \\
\text { (Lecture) }\end{array}$ & 4 & $\begin{array}{l}\text { OGP - Organic Chemistry } \\
\text { (Lab Practical + Seminar) }\end{array}$ & 9 & & & BOK - Toxicology & 4 & \\
\hline & & & & & & & $\begin{array}{c}\text { Introduction to Biochemistry (Lecture) } \\
\text { + Fundamentals of Biochemistry I } \\
\text { (lecture) / Fundamentals of } \\
\text { Biochemistry II + Basic Practical } \\
\text { Course in Biochemistry (Lecture + Lab } \\
\text { Practical) (4 + } 8 \text { ECTS) }\end{array}$ & \multirow[t]{2}{*}{12} & \\
\hline & & & & & & & $\begin{array}{c}\text { Macromolecular Chemistry I (Lecture) / } \\
\text { Basic Practical Course } \\
\text { Macromolecular Chemistry (Lab } \\
\text { Practical) }(6+6 \text { ECTS) }\end{array}$ & & 29 \\
\hline \multirow[t]{2}{*}{ 5. Se } & $\begin{array}{c}\text { AC III - Ring Lecture Methods and } \\
\text { Advanced Inorganic / Materials } \\
\text { Chemistry (Lecture) }\end{array}$ & 6 & OC III - Organic Chemistry III (Lecture) & 4 & $\begin{array}{l}\text { PC III - Physical Chemistry III } \\
\text { (Lecture) }\end{array}$ & 5 & $\begin{array}{l}\text { BOK - elected from Center for Key } \\
\text { Competences }\end{array}$ & 4 & \\
\hline & $\begin{array}{c}\text { AGP - Inorganic and Materials } \\
\text { Chemistry (Lab Practical + Seminar) }\end{array}$ & 9 & & & $\begin{array}{l}\text { Exercises Physical Chemistry III } \\
\text { (Tutorial) }\end{array}$ & 3 & & & 31 \\
\hline \multirow{3}{*}{ 6. Se } & \multicolumn{7}{|c|}{ Method Course: Methods of the Field for the Bachelor Thesis (in part integrated to thesis work) } & 10 & \multirow[b]{3}{*}{25} \\
\hline & \multirow{2}{*}{\multicolumn{7}{|c|}{$\begin{array}{c}\text { Bachelor Thesis Work (typically associated to a Doctoral Researcher) } \\
\text { Public Presentation of the Results of the Bachelor Thesis }\end{array}$}} & 12 & \\
\hline & & & & & & & & 3 & \\
\hline
\end{tabular}

Fig. 2. Overview on the integration of the lecture series $A A C$ - General and Inorganic Chemistry into the degree program of the Bachelor of Science - Chemistry. 
these students that only got their admission with the final exam/ retest, we have set up a second lab practical 'Introductory Course Chemical Procedures' starting mid-April and finishing just before the next scheduled lab practical on 'Analytical Chemistry' that starts in mid-May.

\subsection{Accompanying Measures}

Note that at universities in the state of Baden-Württemberg no tuition fees are taken. There was a short period, when moderate tuition fees of $500 €$ per term had to be paid and, in that time, we introduced accompanying tutorial seminars in small groups (10 to 15 students) on a weekly basis that did cost the institute roughly 40,000 € per year. Yet, we were rather dissatisfied with the outcome: It did not help that the students were transformed from being dependent pupils into independent students, as the attitude in the courses was more a 'leaning back' and 'see what the tutor has to present'. When the money from the tuition fees was cut, we introduced for around a quarter of the prior costs the Dulfab (Denk- und Lernfabrik = think and learn factory), where the students have the chance to discuss their problems with the tutor and in addition meet other students in the same situation and thereby automatically form independent study groups. This often has more the character of a Study Café, where the students discuss the practice sheets and old written exams as a preparation for their examinations. The impression from the last five years is that this system, where the initiative has to come from the students, is superior (but as usual, never perfect).

\section{Structure and Realization of the AAC-Lectures}

On the technical side of the experimental AAC-lecture, we work in a lecture theatre with 420 seats and that is equipped with the option to perform experiments including movable fume hoods (Fig. 3c). In addition, we use three beamers pointing on one very large central projection screen and two large side screens (Fig. 3a). With a remote control all three beamers can be addressed within seconds and content can be switched from one screen to the other. The overall setting in two teaching situations is shown in Fig. 3a and b. One lab technician, in intense lectures with often 10 to 15 experiments also assisted by a second technician, performs the experiments (Fig. 3c,e). All experiments are filmed live on site by a video camera that projects the visual details onto the screen as in Fig. 3b,d. All take home messages for the students are handwritten on paper and projected with a visualizer (document camera) to the screens (Fig. 3a,b).

\subsection{Typically Encountered Teaching Situations in the AAC-Lecture}

Two independent teaching situations are typically encountered; both of which are included with Fig. 3a-e:

a) Explaining the reaction/concept, in part supported by figures/ drawings/pictures. Writing down the take home message for the students (Fig. 3a).

b) Performing the experiment that includes the reaction/visualizes the concept described under a) as in Fig. 3b.

In teaching situation a), often first the figure/picture/drawing around that we explain a content is projected on the central large screen. When starting to write down take home messages or the reaction that is performed in b), the screens are switched and the figure/picture drawing is now shifted to the side screen and the visualizer projects the handwritten take home message on the large central screen.

In teaching situation $b$ ), after the reaction or concept that has been delineated and was written down, we again switch the screens. Now, the handwritten take home is projected on the side screens and the experiment is performed and projected on the large central screen. After some discussion of the experiment, it is switched to the side screen and the take home message again put to the central position and some observations or augmentations are annotated to the writing.

This dynamic switch between the different screens takes a bit of experience and agreement with the team, but it is very helpful to allow for a seamless inclusion of experiments into the flow of the lecture. In addition, this combination is helpful for the students, as they first write down the equation, then watch and experience the experiment and finally add notes to this. In such a situation, the knowledge appears to be more digestible and one automatically reduces the speed to a level tolerable to students in the first semester.

\subsection{Setting of and Typically Encountered Teaching Situations in the AAC-Companion Lecture}

The AAC-companion lecture is strategically given by another, second lecturer. We typically switch between a lecturer from more molecular chemistry and one from more solid-state/materials chemistry. This intends to increase the understanding of the topics, as two different people from different perspectives give their best to explain the content. The scope of this lecture is to provide a more in-depth explanation of the topics, as the AAC-lecture has sometimes to remain closer to the surface to allow for the multi-
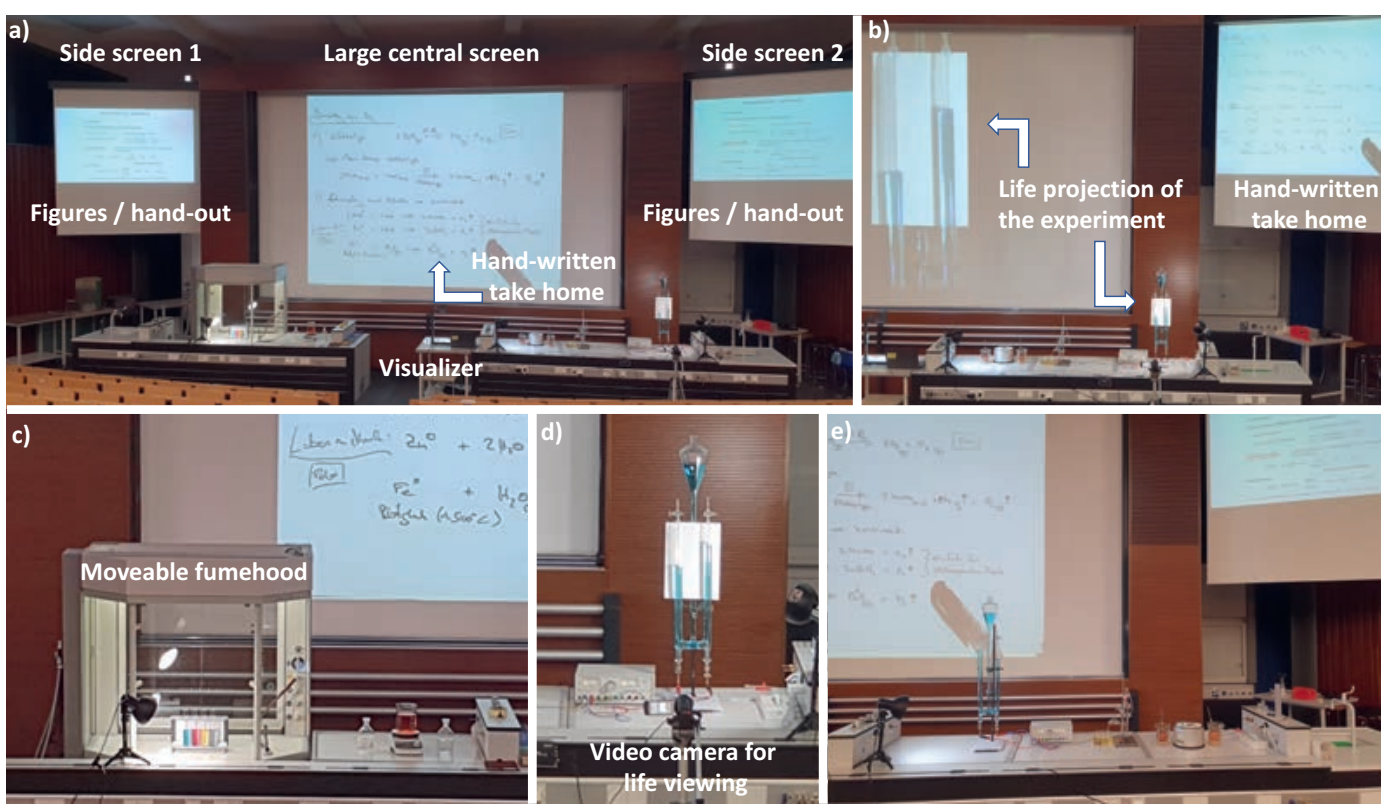

Fig. 3. Typical setup of the AAClecture with the three screens, multiple prepared experiments, the video camera for life viewing and the visualizer for the handwritten notes. a) Teaching situation 'a)' in the text. b) Teaching situation 'b)' in the text. c-e) Close-ups including the moveable fumehood, video camera with experimental set up (here water electrolysis with the $\mathrm{H}_{2}$ - and $\mathrm{O}_{2}$ volumes in 2:1 ratio) and other prepared experiments. All are on moveable tables, to be quickly removed from the lecture hall to the preparative laboratory, which is located behind the screens. 
purpose use including non-chemistry students. Thus, the 15 lectures take up the concepts from the experimental lecture and spend more time and details in concepts and background to electronic structure, bonding, thermodynamics, kinetics, acid-base theories, redox and electrochemistry. The style of the lecture is based on a presentation of slides with ample time for explanation. As the basic aspects were already delineated in the experimental AAC-lecture, we spent quite some time to dive deeper into the topics and make worked examples to allow for a more comprehensive understanding. The lectures are not synchronized, and for some time, e.g. with respect to introducing electronic structure and molecular orbital theory, the topics lag behind the experimental lecture, but meet around Christmas, with the goal to finish the general chemistry part joined with lecture 9 (AAC-companion) and 18 (AAC-lecture). The New Year then starts with the chemistry of the elements, again, the experimental AAClecture being more descriptive and phenomenological including experiments and the AAC-companion being more explicit in terms of the explanation of underlying theories and concepts.

\subsection{Accompanying Measures}

To facilitate independent study of the topics at home by the students, we have agreed on one book that should cover the basics for the first year. It is helpful to agree on one book and we regularly cross-reference to this and suggest exercises from this book. In addition, we follow roughly the structure of this book. The lecturers are free to choose the most appealing book to them. In addition, all the projected content, i.e. figures/drawings/pictures as well as the basic written content is provided at the beginning of the very first lecture password protected to the students as PDF-files labelled according to the hour of the lecture, i.e. AAC_1.pdf. Nowadays many students use these files to digitally write in them, others print them out and add comments. But, the very large majority does keep them separate and manually writes down our take home content as the essence of the lecture series.

\section{Content of the AAC-Lectures}

The lectures address both general chemistry - theory, concepts, methods - as well as an exemplary overview to the chemistry of the elements. The latter mainly focusses on the main group elements and especially addresses industrial processes, but also extending to some selected transition metal chemistry in excess to the redox and complex chemistry already included with the general part.

\subsection{Topics of the General Chemistry Part of the AAC-Lecture}

The lecture starts with zero knowledge, as in principle one could study chemistry without having any prior contact to chemistry in school. Yet, the pace is considerable and already in the first lecture we reach Dalton's laws and thus can enter stoichiometry. After having introduced the atom, we come to the atomic structure (AAC_2) and extend from the atom to the molar view and soon reach thermodynamics as a basis for any energetic evaluation or prediction of the outcome of a reaction (AAC_3). Initially this is based on inner energy and enthalpy, but already introducing energy conservation and the Hess theorem (valid for state functions), also in the context of enthalpies of formation. The AAC_4 lecture returns to the electronic structure of atoms and introduces the particle-wave dualism for electrons and finally leads to the introduction of atomic orbitals. Having introduced electrons, we again return to properties related to electrons, i.e. ionization energies and electron affinities and combine them with thermodynamics to salt formation and the simple sodium chloride structure (AAC_5; nice experiment: Sodium-sun, burning $\mathrm{Na}$ in $\mathrm{Cl}_{2}$-atmosphere). Having introduced salt formation as the first simple chemical bonding concept, in AAC_6 we address the chemical bond in molecules, introduce Lewis formulae and electronegativity as a consequence of polar bonds (Pauling). The AAC_7 lecture is devoted to mo- lecular structure starting with simple VSEPR theory, over hybrid orbitals to molecular orbital theory at elementary level. But, by this time we have introduced gaseous molecules like $\mathrm{H}_{2}$, and in AAC_ 8 the relations among ideal and real gases are introduced. My favourite experiment in this hour is devoted to kinematic gas theory and the average velocity of a gas molecule as function of molecular weight: Thus, if you take absorbent cotton and soak it with concentrated ammonia $\left(M_{\mathrm{r}}=17 \mathrm{~g} \mathrm{~mol}^{-1}\right.$; cotton\#1) as well as concentrated hydrochloric acid $\left(M_{\mathrm{r}}=36.5 \mathrm{~g} \mathrm{~mol}^{-1}\right.$; cotton\#2) and place both at the same time at the opposite ends of an about $30 \mathrm{~cm}$ long glass tubing, most students will expect formation of the colourless $\left[\mathrm{NH}_{4}\right] \mathrm{Cl}$ mist exactly in the middle. Yet, the lighter ammonia diffuses much faster than the heavier hydrogen chloride, and the $\left[\mathrm{NH}_{4}\right] \mathrm{Cl}$ mist forms much closer to the hydrochloric acid cotton\#2. If you place a black piece of paper behind this tubing and place some lighting, this $\left[\mathrm{NH}_{4}\right] \mathrm{Cl}$ formation is very well visible as white mist. With this knowledge at hand, the consequences of polar bonds and intermolecular interactions including the anomalies of the light hydrogen-substituted molecules ammonia, water and hydrogen fluoride are used to bridge to liquid and solid properties and the phase diagram (AAC_9). Next, simple solidstate arrangements such as closed packings of spheres are introduced and automatically lead to metal and salt structures. Now, solutions come into the focus, including Raoult/Henry and the colligative properties in AAC_10. A nice experiment here demonstrates osmotic pressure using a radish as a natural membrane. With the number of particles being relevant, in AAC_11 it is about time to return to thermodynamics and introduce entropy/Gibbs energy leading over to chemical equilibrium. The equilibrium constant is the bridge to kinetics and reaction velocity, order and rate constants as well as transition state theory (AAC_12). Having at hand the physical chemical fundamentals, in AAC_13 the driving forces for different types of chemical reactions - metathesis, acid-base, redox, complex formation - are introduced. AAC_14 returns to chemical equilibrium and is devoted to worked examples using the law of mass action, i.e. ammonia formation, the Boudouard-equilibrium, sulfur trioxide formation and nitrous oxide decomposition. In the next lesson, Brønsted and Lewis acid-base theories are addressed (AAC_15) and further worked on with aspects of the solvent water, $\mathrm{pH}$-value, buffers and simple titrations in AAC_16. More background, the theory behind using indicators in various titrations and extension to consequences of solubility product, complex formation constants and precipitation reactions is given in $\mathrm{AAC}_{-}$17. Lecture $\mathrm{AAC}_{-} 18$ then closes the general chemistry part by concentrating on electrochemistry, redox potentials, electrolysis and overpotentials, batteries and the electrochemical series. This is the endpoint of the lecture for students from molecular medicine.

\subsection{Topics of the Inorganic Chemistry Part of the AAC-Lecture}

Lecture AAC_19 starts the chemistry of the elements with hydrogen, its chemistry, compounds and applications. The next lesson deals with the chemistry of halogens, including chlorine-alkaline electrolysis and the importance of the overpotentials on the formed compounds (AAC_20). The bridge to oxygen in AAC_21 are oxoacids of the halogens and their synthesis, properties and applications. In addition to oxygen, ozone and the background to the ozone hole are given. The chemistry of the chalcogens $\mathrm{S}, \mathrm{Se}$ and Te are the subject of AAC_22 including the Claus-process and sulfuric acid production before we turn in AAC_23 to nitrogen, ammonia (Haber-Bosch-process), hydrazine and nitric acid and relatives. AAC_24 is devoted to the heavier pnictogens $\mathrm{P}, \mathrm{As}, \mathrm{Sb}$ and $\mathrm{Bi}$ with a clear focus on phosphorus. Next the inorganic chemistry of carbon is described before turning to elemental silicon, including photovoltaic and semiconductor qualities in AAC_25. The following lesson AAC_26 includes the chemistry of silicon 
compounds with silicates/glasses and some chemistry of the heavier homologues as well as the lead-acid battery. AAC_27 highlights the simpler boron chemistry from the elemental structure to compounds before lesson AAC_28 addresses aluminium, its production and compounds and as an excursus the technical relevant metal production processes in general. The chemistry of the main group elements is completed in AAC_29 that briefly summarizes the chemistry of alkaline and earth alkaline metals, including calcite, gypsum and cement production. Here, we also experimentally demonstrate the processes occurring inside a lithium ion battery. Last, not least, the closing lecture AAC_30 introduces selected chapters of transition metal chemistry, with a focus on complex formation and d-orbitals, magnetism and redox reactions - typically accompanied by selected examples from iron and manganese chemistry. Here a beautiful experiment is the slow reduction of violet permanganate $\left[\mathrm{Mn}^{\mathrm{VII}} \mathrm{O}_{4}\right]^{-}$over the coloured oxidation states VI and V to insoluble $\mathrm{Mn}^{\mathrm{IV}} \mathrm{O}_{2}$. Quite impressive is also the fresh preparation of pyrophoric iron by thermal decomposition of iron oxalate.

\subsection{Noticeable Developments among the Students in the AAC-Lecture}

The scope of the lecture as outlined in Sections 4.1 and 4.2 should bring all chemistry students regardless of their pre-education in chemistry to a similar level that allows them to progress in their program. Yet, one notices that especially in the first hours, some of the students that were in closer contact to chemistry prior to starting their degree studies, feel superficially secure with the topics. Yet, the full dimensions are often not visible for them and thus, the first written exam after five weeks, which typically has a terrible success rate, grounds them and wakes them up in time to steadily work with the lectures progressing. Apparently, the experimental education that starts just in the New Year with the 'Introductory Course Chemical Procedures' is very helpful, as those that directly enter the course very frequently pass the entire degree program. In general, one may say that those students that keep up with the schedule, even if they have to take the second chance for the lab course 'Introductory Course Chemical Procedures' in mid-April, have a large chance to succeed with the degree program. Yet, the failure rate among the few students that wait another year to be eligible for this lab course, when they missed both entrance options, is very high and we do not recommend this option.

\section{Impact of the Corona Crisis on the Current and Future AAC-Lectures}

As usual there are good and bad sides to any crisis. Apart from heavily affecting any teaching and especially also the lab work for students and researchers, we were forced to use the full opportunities of digital teaching. In the institute we rather soon (in
May) got the very clear impression that the Corona crisis will prevent any larger lecture course like the AAC-lectures with 400-450 participants from being held in the winter term. In addition, to all of the institute staff, experimental work is very close and very important for their way of thinking and teaching. Thus, we immediately started to prepare videos of all the roughly 250 experiments to be held within the regular AAC-lecture. By September this was finished and the videos were edited so that they could be integrated into the presentation file that forms the basis for the digitized video form of the lecture. The MP4 files of the lecture now can be streamed by the students asynchronous at any time they want to from the respective place in our online study portal (https://ilias.uni-freiburg.de/). Although this meant a huge effort for the entire team, we are rather content by the fact that the full year had to be converted to a digital format, as the acquired and developed digital files will be refined in future and kept as a tutorial and recapitulation for the students of future years. Without the urgent need to perform this task as a consequence of the crisis, this would have never taken place to this level and extent. But future students may profit. We'll see...

\section{Concluding Remarks}

I hope the above delineated text gives an impression on the style and philosophy behind the demand for an experimental chemistry lecture at the ALU in Freiburg i. Br. All lecturers from our institute rely heavily on experimental expertise, sometimes being an art rather than a trade, and thus we strongly believe in the value and magic of well-performed experiments as part of the chemical education. Also, in times of always decreasing budgets we keep this value high and do believe that students learn an invaluable attitude towards the importance of being capable to perform experiments. And this is chemistry, the magic of bringing matter to structures, properties and finally function. But, it needs the experiment..

\section{Acknowledgements}

I warmly thank Mrs. Cordula Serr-Gehring and Mr. Bouhmahdi Benkmil, who arranged the realistic teaching scenario shown with Fig. 3 in our lecture hall at my request. These lectures would be impossible without their invaluable help!

Received: December 14, 2020

\section{License and Terms}

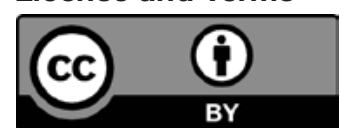

This is an Open Access article under the terms of the Creative Commons Attribution License CC BY 4.0. The material may not be used for commercial purposes.

The license is subject to the CHIMIA terms and conditions: (http:// chimia.ch/component/sppagebuilder/?view=page $\& i d=12$ ).

The definitive version of this article is the electronic one that can be found at https://doi.org/10.2533/chimia.2021.9 